\title{
Nanoscale
}

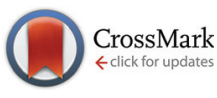

Cite this: Nanoscale, 2015, 7, 1642

Received 13th October 2014, Accepted 15th December 2014

DOI: $10.1039 / c 4 n r 06033 d$

www.rsc.org/nanoscale

\section{High-performance semitransparent perovskite solar cells with solution-processed silver nanowires as top electrodes $\dagger$}

\author{
Fei Guo, ${ }^{\text {a }}$ Hamed Azimi, ${ }^{a}$ Yi Hou, ${ }^{a, c}$ Thomas Przybilla, ${ }^{b}$ Mengyao Hu, ${ }^{a}$ \\ Carina Bronnbauer, ${ }^{a, c}$ Stefan Langner, ${ }^{a}$ Erdmann Spiecker, ${ }^{b}$ Karen Forberich ${ }^{a}$ and \\ Christoph J. Brabec*a,d
}

In this work, we report efficient semitransparent perovskite solar cells using solution-processed silver nanowires (AgNWs) as top electrodes. A thin layer of zinc oxide nanoparticles is introduced beneath the AgNWs, which fulfills two essential functionalities: it ensures ohmic contact between the $\mathrm{PC}_{60} \mathrm{BM}$ and the AgNWs and it serves as a physical foundation that enables the solution-deposition of AgNWs without causing damage to the underlying perovskite. The as-fabricated semitransparent perovskite cells show a high fill factor of $66.8 \%, V_{\text {oc }}=0.964 \mathrm{~V}, J_{\text {sc }}=13.18 \mathrm{~mA} \mathrm{~cm}^{-2}$, yielding an overall efficiency of $8.49 \%$ which corresponds to $80 \%$ of the reference devices with reflective opaque electrodes.

Inorganic-organic halide perovskite solar cells have recently emerged as a promising photovoltaic technology due to their high efficiencies and low-cost processing potential. ${ }^{1-4}$ The exceptional optoelectronic properties of the perovskite crystals such as high carrier mobility and long charge diffusion length promise highly efficient charge separation. ${ }^{5,6}$ These intriguing characteristics make perovskites ideal materials for photovoltaic applications. Since the first device demonstration in 2009, power conversion efficiency (PCE) of perovskite solar cells processed by both vacuum-deposition and solutionprocessing has surged to over $15 \% .^{2,4,7-9}$ The continuous and fast progress in the research related to perovskite solar devices has established them as a serious contestant to the traditional silicon-based panels.

\footnotetext{
${ }^{a}$ Institute of Materials for Electronics and Energy Technology (I-MEET), FriedrichAlexander-University of Erlangen-Nuremberg, Martensstrasse 7, 91058 Erlangen, Germany

${ }^{b}$ Center for Nanoanalysis and Electron Microscopy (CENEM), WW7, FriedrichAlexander-University of Erlangen-Nuremberg, Cauerstrasse 6, 91058 Erlangen, Germany

${ }^{c}$ Erlangen Graduate School in Advanced Optical Technologies (SAOT), Paul-GordanStrasse 6, 91052 Erlangen, Germany

${ }^{d}$ Bavarian Center for Applied Energy Research (ZAE Bayern), Haberstrasse 2a, 91058 Erlangen, Germany. E-mail: fei.guo@ww.uni-erlangen.de,

christoph.brabec@ww.uni-erlangen.de

$\dagger$ Electronic supplementary information (ESI) available. See DOI: 10.1039/ c4nro6033d
}

Together with the considerable efforts devoted to pursuing high efficiencies via improved crystallization of perovskite and searching for low-cost interface materials, ${ }^{4,10-13}$ aesthetic semitransparent perovskite solar cells have been simultaneously receiving growing attention because of their specific application in transparent architectures, ${ }^{14-17}$ such as windows, rooftops, greenhouses and other fashion elements. To achieve efficient semitransparent perovskite devices, both the anode and the cathode of the devices should be highly transparent and conductive in order to minimize the optical and resistance losses. To date, several studies have reported semitransparent perovskite solar cells, but most of these devices employed thin metal films (Al, Ag, Au) as top electrodes which were fabricated based on energy-intensive evaporation processes. ${ }^{15-17}$ It is well known that, in addition to low-cost materials, the cost reduction of photovoltaic devices substantially depends on the ability to use high-throughput coating techniques in combination with roll-to-roll processing. ${ }^{18}$ Despite its importance, however, less attention has been paid to the exploration of solution-processable transparent electrodes for perovskite solar cells.

Carbon based materials have received much attention for use as conducting electrodes for perovskite solar cells, due to their low-cost and high stability. ${ }^{14,19,20}$ For example, Li et al. have recently reported semitransparent perovskite solar cells using carbon nanotubes as top electrodes. It was found that the high sheet resistance of the carbon nanotube films (2-25 k $\Omega$ sq. $^{-1}$ ) adversely limited the device's performance, resulting in low fill factors (FFs) due to the high series resistance of the device. ${ }^{14}$ Moreover, the involved transfer and lamination procedures increased the complexity in device fabrication which is incompatible with large-scale, continuous roll-to-roll manufacturing. Simultaneously, Mei et al. reported the use of printed carbon black/graphite composite material as top electrodes for perovskite solar cells. ${ }^{19,20}$ Although the devices with carbon electrodes exhibited high efficiency and long-term stability, to achieve the desired sheet resistance the carbon black/graphite layer had to be made rather thick (tens of micrometers) which makes the devices non-transparent. 
In this regard, it is significant that solution-processable transparent electrodes should be developed for the construction of semitransparent perovskite devices. In recent years, several solution-processable conducting materials have been extensively investigated as alternatives of ITO for optoelectronic devices, such as touch screen panels, solar cells and light emitting diodes. ${ }^{21}$ Among these proposed materials, silver nanowires (AgNWs) represent one of the most promising materials with benchmark optoelectronic properties of $~ 90 \%$ transmittance at $550 \mathrm{~nm}$ and $<20 \mathrm{ohm} \mathrm{sq.}{ }^{-1}$ sheet resistance that are comparable with the commercial ITO electrode. ${ }^{22,23}$ The use of AgNWs as bottom and/or top transparent electrodes has recently been demonstrated in polymer solar cells, dyesensitized solar cells, copper indium gallium diselenide and silicon solar cells. ${ }^{22-29}$ However, the sensitivity to the surface that the perovskite crystals grow on and the incompatibility between the electrode and the adjacent interface layers have hindered the progress of the implementation of liquid-phase coated electrodes for perovskite solar cells. ${ }^{30}$

In this work, through rational interface engineering in combination with judicious selection of deposition techniques, we demonstrate for the first time facile solution processing of AgNWs as top electrodes for efficient semitransparent perovskite solar cells. We introduce a thin layer of zinc oxide nanoparticles beneath the top AgNW electrodes, which serves as a physical foundation allowing the solution-deposition of the AgNWs and ensures ohmic contact between the $\mathrm{PC}_{60} \mathrm{BM}([6,6]-$ phenyl C61-butyric acid methyl ester) and AgNWs. Due to the excellent compatibility of the solution-processed AgNWs with the underlying interface materials, the as-prepared perovskite solar cells showed full open-circuit voltage $\left(V_{\text {oc }}\right)$ and high FFs comparable to their evaporated counterparts. In addition, due to the high transparency of the AgNW electrode, the resulting semitransparent perovskite devices exhibited a decent visible transparency of $21.5 \%$.

A planar-heterojunction device structure was chosen for our study due to its easy fabrication, inexpensive materials and high efficiencies. ${ }^{4,10,11,30}$ Fig. 1a shows the schematic device architecture of the reference solar cells with a layer sequence of Glass/ITO/PEDOT:PSS/ $\mathrm{CH}_{3} \mathrm{NH}_{3} \mathrm{PbI}_{3-x} \mathrm{Cl}_{x} / \mathrm{PC}_{60} \mathrm{BM} / \mathrm{Ag}$. The perovskite absorber is sandwiched between the PEDOT:PSS and $\mathrm{PC}_{60} \mathrm{BM}$ which serves as an electron and a hole-blocking layer, respectively. As the first step, we grew perovskite crystals from a 3:1 molar ratio of $\mathrm{NH}_{3} \mathrm{CH}_{2} \mathrm{I}$ and $\mathrm{PbCl}_{2}$ precursor solution on PEDOT:PSS coated-ITO substrates. The as-prepared film was characterized using X-ray diffraction (XRD) and a scanning electron microscopy (SEM). Fig. 1b presents the X-ray pattern of the as-grown $\mathrm{CH}_{3} \mathrm{NH}_{3} \mathrm{PbI}_{3-x} \mathrm{Cl}_{x}$ film on Glass/ITO/ PEDOT:PSS. The sharp diffraction peaks of the perovskite are clearly identified, with $14.15^{\circ}, 28.47^{\circ}$ and $43.25^{\circ}$, respectively, (a)

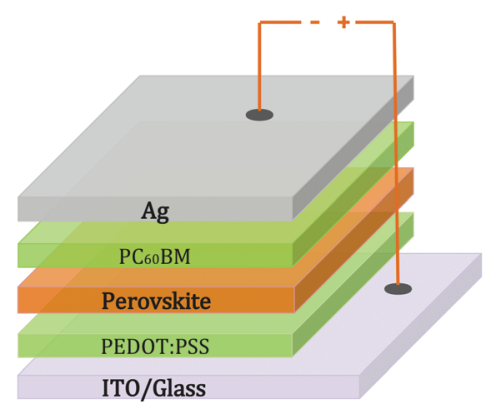

(c)

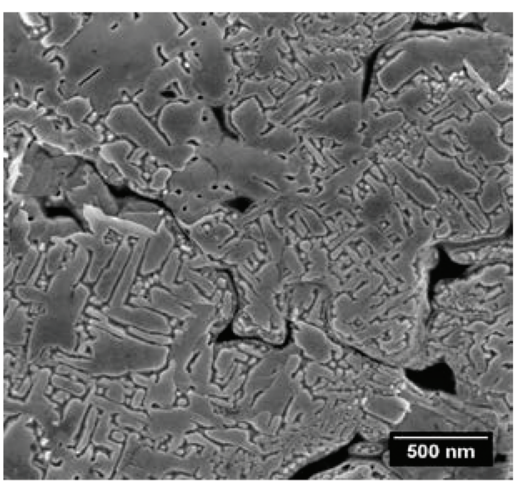

(b)

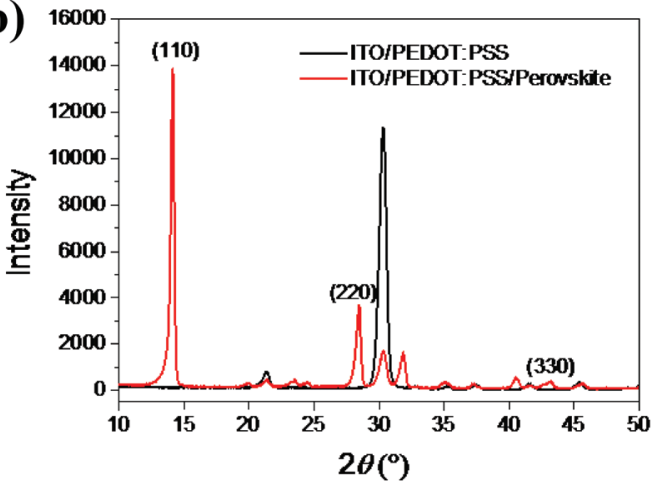

(d)

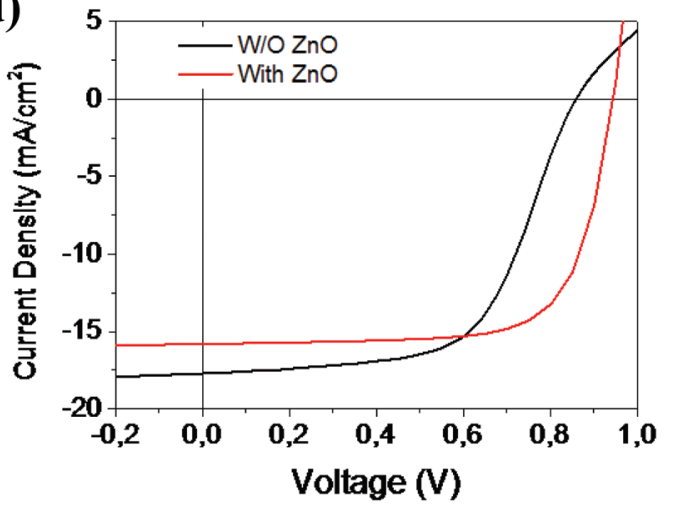

Fig. 1 (a) Schematic architecture of the perovskite reference device. (b) XRD pattern of the perovskite crystals grown on PEDOT:PSS/ITO (red line), with blank sample of the PEDOT:PSS coated ITO substrate for comparison (black line). (c) Top-view SEM image of the as-grown perovskite film. (d) $J-V$ curves of the two devices with and without a layer of $\mathrm{ZnO}$ between the $\mathrm{PC}_{60} \mathrm{BM}$ and $\mathrm{Ag}$ top electrode. 
assigned to the 110, 220 and 330 diffraction peaks, indicating the formation of a perovskite crystalline layer. ${ }^{8}$ A top-view SEM image shown in Fig. 1c indicates that the size of the perovskite crystals is of the order of several hundred nanometers. A typical current density-voltage $(J-V)$ characteristic of a reference perovskite solar cell which was recorded under simulated AM $1.5 \mathrm{G}$ with a light intensity of $100 \mathrm{~mW} \mathrm{~cm}^{-2}$ is shown in Fig. 1d (black curve). The short-circuit current density $\left(J_{\mathrm{sc}}\right), V_{\mathrm{oc}}$ and $\mathrm{FF}$ of a typical reference cell, respectively, are $17.7 \mathrm{~mA}$ $\mathrm{cm}^{-2}, 0.86 \mathrm{~V}$ and $60.5 \%$, yielding a PCE of $9.19 \%$. The key parameters of the device performance are summarized in Table 1. It is noteworthy that no obvious hysteresis of $J-V$ characteristics was observed by changing the voltage scan direction or rates (Fig. $\mathrm{S} 1 \dagger$ ).

We then attempted to replace the vacuum-deposited Ag top electrodes with solution-processed AgNWs. Halide perovskite is known as a water-soluble material, the processing technique should be therefore discreetly chosen to deposit AgNWs from water-based solution. We initially tried both doctor-blading and spin-coating to deposit AgNWs, but an immediate color transformation from dark brown to yellowish was observed once the solution came in contact with the thin $\mathrm{PC}_{60} \mathrm{BM}$ film (Fig. S2†), indicating a fast breakdown of the perovskite. Previously, we have found that spray coating can be used as a reliable coating technique to deposit AgNWs as top electrodes for organic solar cells. ${ }^{26}$ The unique characteristic of ultra-fast drying (in orders of $\mu \mathrm{s}$ ) of the spray coated femtoliter-volume aerosol droplets allows for negligible solvent damage to the underlying thin and soft organic absorber layer. We therefore adopted spray coating to deposit AgNWs from a diluted solution with isopropanol $(1: 3 \mathrm{vol} \%)$, which can further reduce the amount of solvent to interact with the underlying layer due to the low boiling point of isopropanol. As expected, it was observed that the spray coating of AgNWs onto the top of the device (ITO/PEDOT:PSS/perovskite/ $\mathrm{PC}_{60} \mathrm{BM}$ ) did not change the color of the perovskite, which is a strong indication that the perovskite can survive the spray coating with a water-based material. However, the as-prepared devices exhibited almost no photovoltaic behavior (Fig. S3 $\uparrow$ ), probably due to the fact that the non-ohmic contact between the $\mathrm{PC}_{60} \mathrm{BM}$ and $\mathrm{AgNWS}$ is presenting an energy barrier for charge extraction. ${ }^{29}$

Recently, we have found that $\mathrm{ZnO}$ nanoparticles as an electron transport layer in organic solar cells showed excellent compatibility with thermally evaporated $\mathrm{Ag}$ as well as with solution-processed AgNW top electrodes (Fig. S4 $\dagger$ ). ${ }^{31,32}$ Inspired by this finding, we expect that applying an additional electron transport layer $\mathrm{ZnO}$ onto $\mathrm{PC}_{60} \mathrm{BM}$ can act as a mechanical foundation to withstand the solution-deposition of AgNWs and, more importantly as an energy modifier to facilitate electron transport from the perovskite to the AgNW electrode. To confirm the compatibility between the $\mathrm{PC}_{60} \mathrm{BM}$ and $\mathrm{ZnO}$, perovskite devices with top thermally evaporated $\mathrm{Ag}$ electrodes (ITO/PEDOT:PSS/Perovskite/ $\mathrm{PC}_{60} \mathrm{BM} / \mathrm{ZnO} / \mathrm{Ag}$ ) were first constructed. Devices with three different spin coating speeds were fabricated to find the optimal thickness of the $\mathrm{ZnO}$ layer. As shown in Fig. $55, \dagger$ the $V_{\text {oc }}$ of the devices slightly decreased from $\sim 0.95 \mathrm{~V}$ to $\sim 0.87 \mathrm{~V}$ when the coating speed was increased from $1000 \mathrm{rpm}$ to $3000 \mathrm{rpm}$, while the $\mathrm{FF}$ is less sensitive to the thickness of the ZnO layer. The reduced $V_{\text {oc }}$ of the devices with high coating speed is possibly due to the diffusion of the $\mathrm{Ag}$ through the thin $\mathrm{ZnO}$ layer and reduces the built-in potential of the devices. Typical $J-V$ characteristics are presented in Fig. 1d (red curve). Compared to the perovskite device without the $\mathrm{ZnO}$ layer, a remarkable improvement in photovoltaic performance was observed, particularly in terms of $\mathrm{FF}$ and $V_{\mathrm{oc}}$ which were increased from $60.5 \%$ and $0.86 \mathrm{~V}$ to $71.9 \%$ and $0.945 \mathrm{~V}$, respectively, resulting in an enhanced PCE of $10.68 \%$ as compared to 9.19\% of the device without the $\mathrm{ZnO}$ layer (Table 1).

We attribute this performance enhancement to the following two reasons: firstly, as evidenced in the SEM images (Fig. 2a and b), the applied $\mathrm{ZnO}$ layer served as a capping layer which uniformly covered the underlying perovskite and $\mathrm{PC}_{60} \mathrm{BM}$. This effective capping can indeed eliminate possible shunt-paths where the perovskite is not covered by the electron transport layer $\mathrm{PC}_{60} \mathrm{BM}$ (Fig. 2b, 3b and Fig. S6 $\dagger$ ). ${ }^{8,30,33}$ On the other hand, due to a more favorable energy level alignment as well as the formation of an ohmic contact between the interface of $\mathrm{ZnO}$ and $\mathrm{Ag}$, the introduced $\mathrm{ZnO}$ layer serves as an energy bridge to facilitate electron extraction from perovskite to top Ag electrodes (Fig. 2c). ${ }^{29,34}$ As a result, a significantly improved shunt resistance $\left(119.2 \mathrm{k} \Omega \mathrm{cm}^{2}\right.$ as compared to 1.9 $\mathrm{k} \Omega \mathrm{cm}^{2}$ of the device without the ZnO layer) and a reduced series resistance $\left(3.7 \Omega \mathrm{cm}^{2}\right.$ as compared to $10.5 \mathrm{k} \Omega \mathrm{cm}^{2}$ of the device without the $\mathrm{ZnO}$ layer) were obtained which contributed to the enhanced FF and $V_{\text {oc }}$ of the resulting devices (Table 1). ${ }^{35}$

Having successfully incorporated a layer of $\mathrm{ZnO}$ nanoparticles on top of $\mathrm{PC}_{60} \mathrm{BM}$, we now continue to complete the device fabrication by spray coating a thin layer of AgNWs as a top electrode (Fig. 3a). The length and diameter of the AgNWs used in the work are $30 \mu \mathrm{m}$ and $30 \mathrm{~nm}$, respectively. ${ }^{26}$ Fig. $3 \mathrm{~b}$ shows a cross-sectional SEM image of the as-prepared solar cells, which reveals a well-defined layer organization without

Table 1 Summary of photovoltaic parameters of the investigated semitransparent and opaque perovskite solar cells

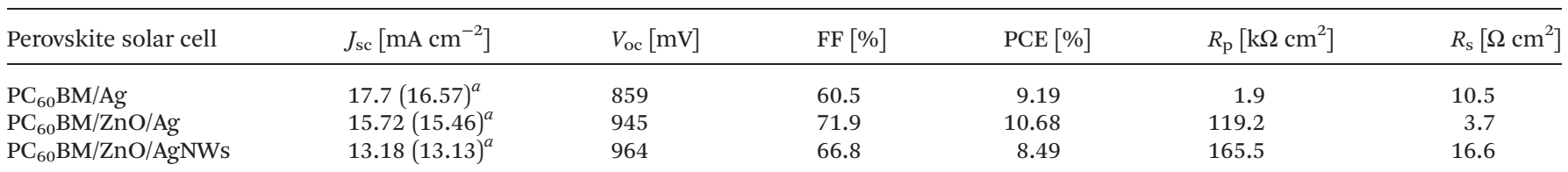

${ }^{a} J_{\mathrm{sc}}$ values were calculated by integrating the EQE spectrum with the AM $1.5 \mathrm{G}$ spectrum. Series $\left(R_{\mathrm{S}}\right)$ and parallel resistances $\left(R_{\mathrm{p}}\right)$ were calculated from the slope of the dark $J-V$ curve close to 2 and $0 \mathrm{~V}$, respectively. 

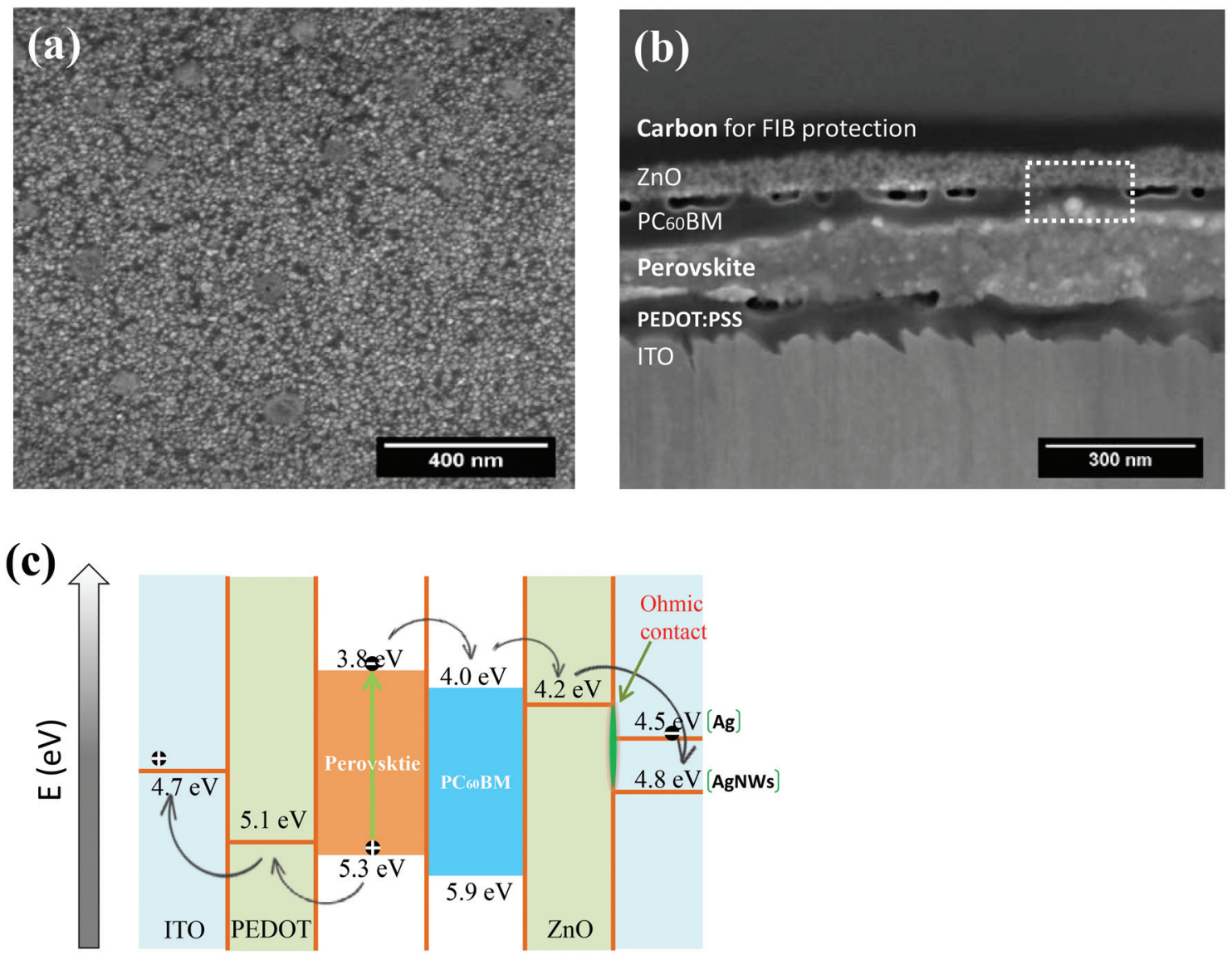

Fig. 2 (a) Top-view SEM image of an incomplete device with a ZnO layer on top of $\mathrm{PC}_{60} \mathrm{BM}$, "Glass/ITO/PEDOT:PSS/Perovskite/PC 60 BM/ZnO". (b) Cross sectional SEM image of the device with the same structure as (a). The white dashed rectangle shows the area where perovskite is hardly covered by $\mathrm{PC}_{60} \mathrm{BM}$. (c) Energy diagram of the devices with a $\mathrm{ZnO}$ layer between $\mathrm{PC}_{60} \mathrm{BM}$ and $\mathrm{Ag}$ (or $\mathrm{AgNWs)}$ ).

layer-by-layer intermixing. We note that the voids in the AgNW network are typically of the order of hundred nanometers. ${ }^{26}$ It is therefore reasonable that not too many wires were observed in our cross sectional image with a small imaging area. Nevertheless, a distinct interface between the ZnO layer and individual AgNWs can be clearly seen, indicating that the ZnO layer is sufficiently robust to support the solution-deposition of AgNWs by spray coating. Overall, these observations anticipate full device performance without detrimental effects from shunting or short-circuiting.

Fig. 3c shows the $J-V$ characteristics of a typical best-performed perovskite solar cell with the solution-processed AgNW top electrode. The key parameters of the device performance are presented in Table 1. During device optimization, more than 60 semitransparent cells with AgNW top electrodes were fabricated; over $90 \%$ of the devices exhibited $V_{\text {oc }}$ values exceeding $0.90 \mathrm{~V}$ and half of them showed FFs of $>60 \%$ (Fig. S7a and S7b $\dagger$ ). Importantly, it was observed that the $V_{\text {oc }}$ of the devices with spray coated AgNWs is less sensitive to the thickness of the $\mathrm{ZnO}$ when the layer thickness is higher than $60 \mathrm{~nm}$. As shown in Fig. S7c and S7d, $\dagger$ the devices showed relatively stable performance with the thick $\mathrm{ZnO}$ layer (i.e. 60 and $90 \mathrm{~nm}$ ), while the thinner $\mathrm{ZnO}$ layer $(30 \mathrm{~nm})$ resulted in inferior performance. These results can be probably attributed to the fact that a too thin $\mathrm{ZnO}$ layer is not capable of preventing solvent damage to the underlying layers during spray coating the AgNWs. Due to the lack of back reflective electrodes, the AgNW based semitransparent cells showed current densities of $\sim 13 \mathrm{~mA} \mathrm{~cm}{ }^{-2}$ which are approximately $2.5 \mathrm{~mA}$ $\mathrm{cm}^{-2}$ lower than their opaque counterparts. To verify the accuracy of the measured current density under a simulated solar spectrum, we performed external quantum efficiency (EQE) characterization. As shown in Fig. 3d, the AgNW based solar cell shows approximately $10 \%$ lower quantum efficiency in the range of $450-750 \mathrm{~nm}$ as compared to the opaque counterpart. We note that thin-film solar cells with solution-processed top electrodes generally showed relatively low FFs compared to their evaporated counterparts. ${ }^{26-29}$ The decrease in FFs can be mainly attributed to the limited current injection due to the higher contact resistance between the solution-processed electrodes and the underlying interface layer. As shown in Table 1, the semitransparent cell with a solution-processed AgNW top electrode showed a high series resistance of $16.6 \Omega \mathrm{cm}^{2}$ which is $\sim 5$ times higher than the evaporated counterpart. Nevertheless, slightly reduced yet still high FFs of $\sim 67 \%$ were obtained for our best-performed semitransparent perovskite devices 
(a)

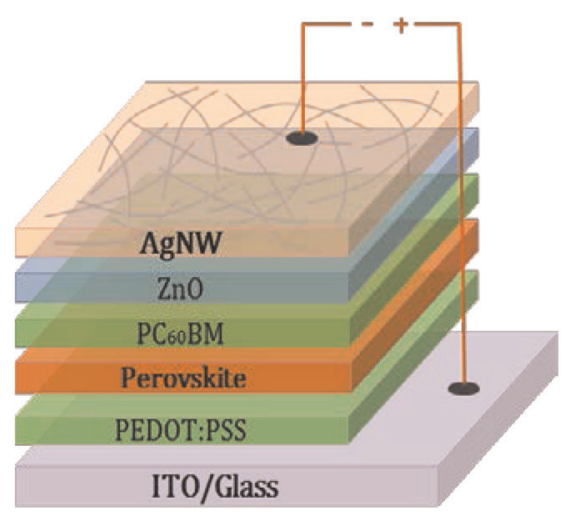

(c)

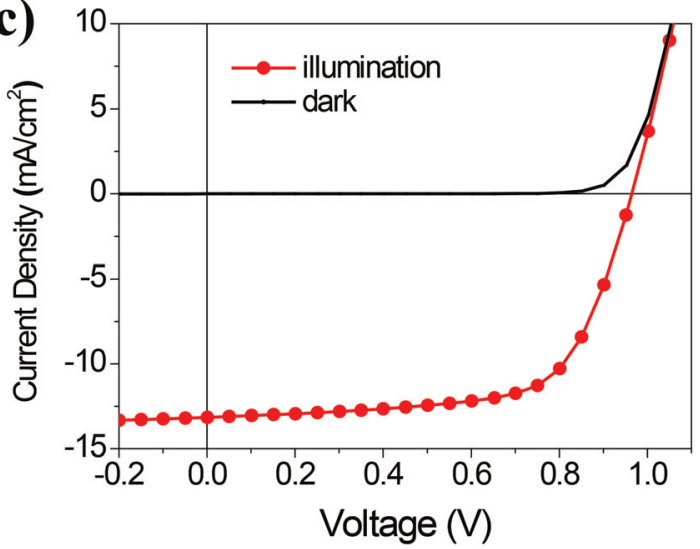

(b)

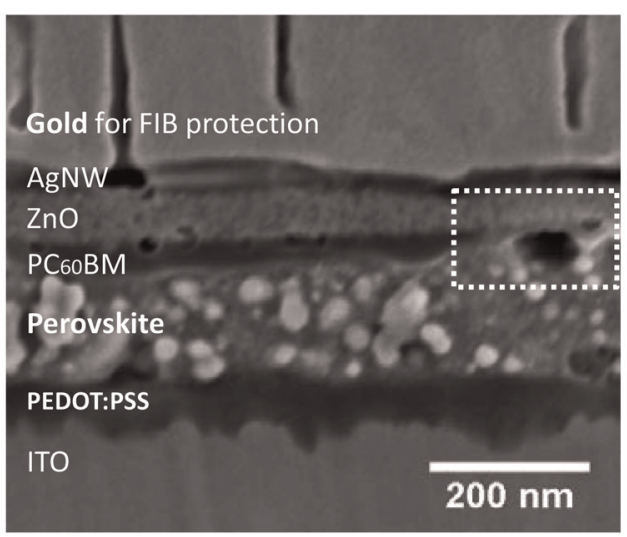

(d)

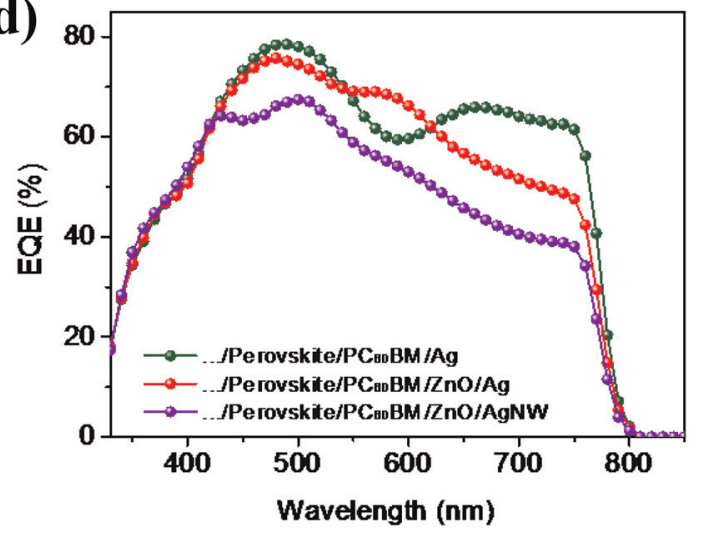

Fig. 3 (a) Schematic structure of the devices with solution-processed top AgNWs. (b) Cross sectional image of the whole device stack. The white dashed rectangle shows the area where perovskite is not covered by $\mathrm{PC}_{60} \mathrm{BM}$. (c) $J-V$ curves of the devices measured under illumination (red curve) and in the dark (dark curve). (d) EQE characteristics of the three types of devices studied in this work.

with AgNW top electrodes. Overall, a high PCE of up to $8.5 \%$ of the semitransparent perovskite solar cells was achieved, which corresponds to $80 \%$ of the reference device with an evaporated opaque electrode.

Semitransparent perovskite solar cells have been recently reported by several groups, but the investigated devices employed either thermally evaporated thin metal films or transferred carbon nanotubes as top electrodes. ${ }^{14-17}$ Herein, our semitransparent perovskite devices were fabricated using low-temperature solution-processed AgNW films as top electrodes, which is of great significance for the realization of the cost potential of this solar technology. As shown in Fig. 4a, our semitransparent device with $\sim 150 \mathrm{~nm}$ thick perovskite exhibits an average visible transparency (AVT) of 28.4\%, which is similar to the value reported by Roldán-Carmona. ${ }^{16}$ Significantly, the high average transmittance of $50.3 \%$ ranging from $600 \mathrm{~nm}$ to $900 \mathrm{~nm}$ suggests a great potential to improve the overall device efficiency by making use of tandem solar cells either in series or in parallel connection.

In order to better understand the interdependency between efficiency and transparency, we performed optical simulations using the transfer matrix method. The optical constants
(Fig. $4 \mathrm{~b}$ and Table $\mathrm{S} 1 \dagger$ ) of the perovskite film were obtained by measuring the reflection and transmission spectra and subsequently modeled with the software NIKA. ${ }^{36}$ Fig. $4 \mathrm{c}$ shows the transparency and the $J_{\mathrm{sc}}$ depending on the perovskite layer thickness. We observe a good agreement between the calculated and the measured values at our experimental layer thickness of $150 \mathrm{~nm}$. It has to be noted that we used an IQE value of $100 \%$, obtained from the comparison with the measured $J_{\mathrm{sc}}$ value, confirming the excellent transport properties of the perovskite layer and the whole device. ${ }^{37}$

It should be mentioned that we have observed a poor stability of the perovskite solar cells with AgNW top electrodes. The devices underwent a fast degradation even when they are kept in a $\mathrm{N}_{2}$-filled glovebox (Fig. S8 $\dagger$ ). We speculate that this fast degradation is most likely induced by chemical reactions between the sublimed $\mathrm{I}^{-}$and $\mathrm{Ag}^{+}$with formation of $\mathrm{AgI}$ which is an insulating material. The resulting AgI can adversely increase the series resistance of the devices as well as the sheet resistance of the AgNW electrode thereby impairing the charge extraction. Nevertheless, we expect that significant stability enhancement can be achieved if a compact interface layer is used to physically isolate the perovskite absorber from top 
(a)

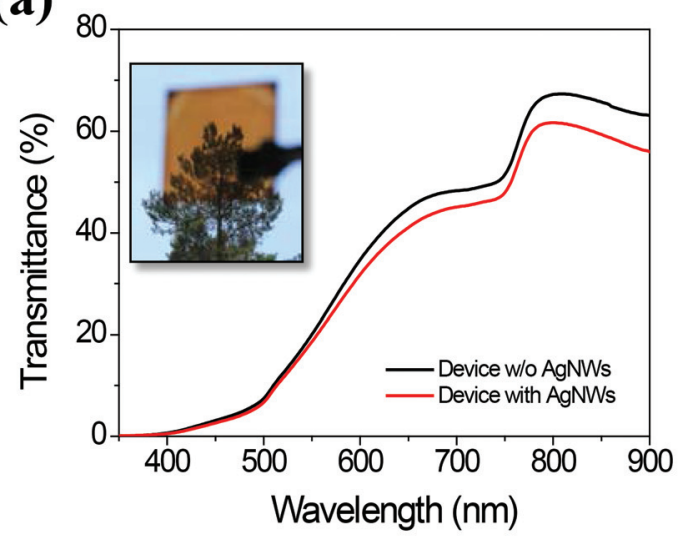

(c)

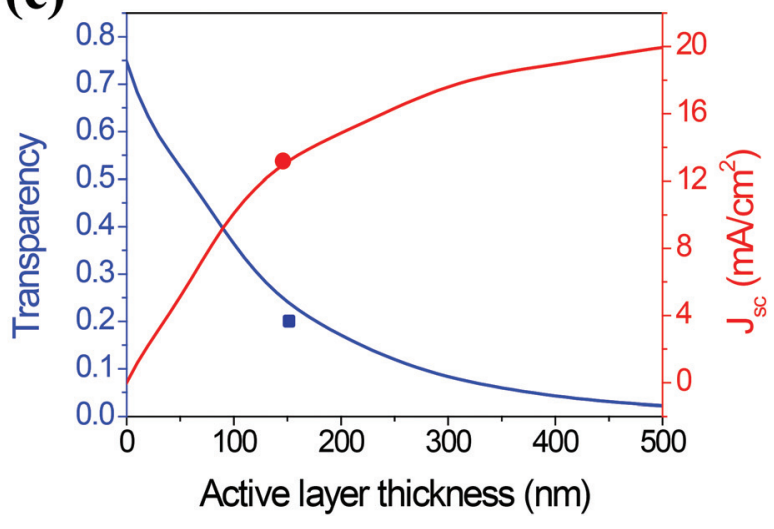

(b)

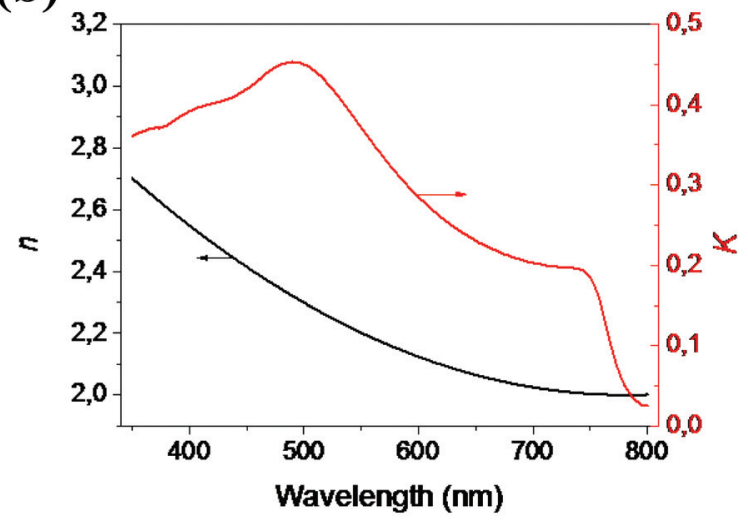

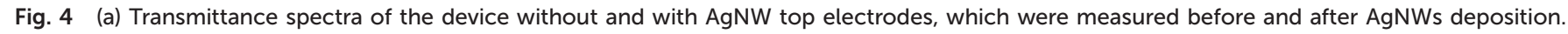

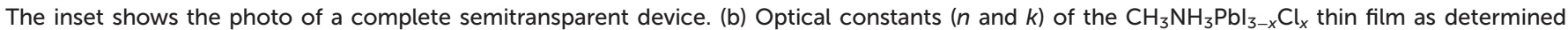

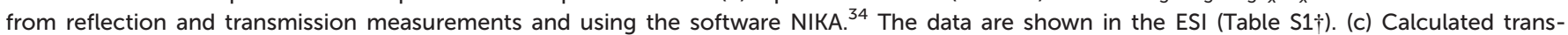

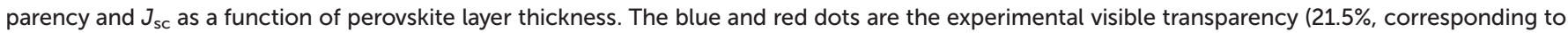
$28.4 \%$ AVT of the device) and $J_{\text {sc }}$ values.

AgNWs. Alternatively, other inactive conducting materials to iodine such as graphene and nanotubes are promising candidates for long-term stable solution-processed semitransparent perovskite devices. ${ }^{14,19,20}$

\section{Conclusions}

In summary, through a rational interface engineering and careful choice of deposition techniques, we demonstrated for the first time efficient semitransparent perovskite solar cells with solution-processed AgNW top electrodes. The introduced $\mathrm{ZnO}$ layer between $\mathrm{PC}_{60} \mathrm{BM}$ and top AgNWs was found to be decisive for device functionality. It not only enables the solution deposition of AgNWs without any damage to the underlying layers but also ensures ohmic contacts between $\mathrm{PC}_{60} \mathrm{BM} /$ $\mathrm{ZnO}$ and $\mathrm{ZnO} / \mathrm{AgNWs}$. The resulting semitransparent perovskite solar cells showed a high PCE of $8.5 \%$ and an AVT of $28.4 \%$. These results suggest that high-performance perovskite solar cells can be realized with a significantly reduced production cost by incorporating low-cost materials and through a fully solution processed route.

\section{Methods}

\section{Materials}

$\mathrm{PbCl}_{2}$ (99.98\%, obtained from Alfa Aesar) and $\mathrm{CH}_{3} \mathrm{NH}_{3} \mathrm{I}$ (provided by Dyenamo) mixed with a molar ratio of $1: 3$ were dissolved in dimethyl formamide in a concentration of $30 \%$. The precursor solution was stirred at $60{ }^{\circ} \mathrm{C}$ for 3 hours inside a $\mathrm{N}_{2}$-filled glovebox before use. Prior to spin coating, the solution was filtered using a $0.2 \mu \mathrm{m}$ PTFE syringe filter. $\mathrm{PC}_{60} \mathrm{BM}(99.5 \%$, Solenne BV) was dissolved in chlorobenzene with a concentration of $20 \mathrm{mg} \mathrm{mL}^{-1}$ and stirred at $60^{\circ} \mathrm{C}$ for 4 hours before use. ZnO nanoparticles dispersed in isopropanol (Product $\mathrm{N}-10$, $2.5 \mathrm{wt} \%$ ) were kindly provided by Nanograde AG.

\section{Device fabrication}

The patterned ITO substrates were subsequently ultrasonically cleaned with acetone and isopropanol for 10 minutes each. On the cleaned ITO substrate, a layer of PEDOT:PSS (Clevios ${ }^{\mathrm{TM}}$ $\mathrm{P}$ VP AI 4083) was deposited by doctor blading at $50{ }^{\circ} \mathrm{C}$ and annealed at $140^{\circ} \mathrm{C}$ for 10 minutes resulting in a $\sim 40 \mathrm{~nm}$ thick film. Afterwards, the substrates were transferred into the glovebox for the deposition of perovskite absorber, $\mathrm{PC}_{60} \mathrm{BM}$ and 
ZnO layers. The filtered perovskite precursor was spin-cast at $2000 \mathrm{rpm}$ for 45 seconds. The crystallization of the perovskite was performed by annealing the as-casted film from $50{ }^{\circ} \mathrm{C}$ to $110^{\circ} \mathrm{C}$ with duration of 40 minutes, and subsequently kept at $110{ }^{\circ} \mathrm{C}$ for another 40 minutes. The thickness of the $\mathrm{CH}_{3} \mathrm{NH}_{3} \mathrm{PbI}_{3-x} \mathrm{Cl}_{x}$ layer is approximately $150-200 \mathrm{~nm} . \mathrm{PC}_{60} \mathrm{BM}$ solution was then spin-cast onto the $\mathrm{CH}_{3} \mathrm{NH}_{3} \mathrm{PbI}_{3-x} \mathrm{Cl}_{x}$ layer at $1000 \mathrm{rpm}$ for 45 seconds. For devices with the $\mathrm{ZnO}$ interface layer, $\mathrm{ZnO}$ solution was spin-cast onto $\mathrm{PC}_{60} \mathrm{BM}$ at three different speeds (1000 rpm, $2000 \mathrm{rpm}$ and $3000 \mathrm{rpm}$ ) for 45 seconds to achieve layer thicknesses of around $90 \mathrm{~nm}, 60 \mathrm{~nm}$ and $30 \mathrm{~nm}$, respectively. For all opaque devices, $100 \mathrm{~nm}$ thick $\mathrm{Ag}$ was deposited on the $\mathrm{PC}_{60} \mathrm{BM}$ or $\mathrm{ZnO}$ layer through a shadow mask under a vacuum of $10^{-6}$ torr. To complete the devices with top AgNW electrodes, AgNWs diluted with isopropanol (1:3 vol\%) were deposited on the $\mathrm{ZnO}$ layer at $45^{\circ} \mathrm{C}$ under an air atmosphere using a home-built spray coater. ${ }^{23}$ The obtained $\sim 120 \mathrm{~nm}$ thick AgNW film had a sheet resistance of $\sim 20 \mathrm{ohm} \mathrm{sq.}{ }^{-1}$ and a transmittance of $\sim 85 \%$ at $550 \mathrm{~nm} .^{26}$

\section{Device characterization}

$J-V$ characteristics of all the devices were measured using a source measurement unit from BoTest. Illumination was provided by a Newport Sol1A solar simulator with an AM 1.5G spectrum and light intensity of $100 \mathrm{~mW} \mathrm{~cm} \mathrm{~cm}^{-2}$, which was determined by a calibrated crystalline Si-cell. If not specified elsewhere, all the $J-V$ curves were measured with the forward direction at a sweep delay of $50 \mathrm{~ms}$. During device characterization, a shadow mask with an opening of $10.4 \mathrm{~mm}^{2}$ was used. The EQE spectra were recorded using an Enli Technology (Taiwan) EQE measurement system (QE-R), and the light intensity at each wavelength was calibrated with a standard single-crystal Si photovoltaic cell. All the $J-V$ and EQE characteristics were recorded with illumination from the ITO side. Thicknesses of the films were measured by a profilometer (Tencor Alpha Step). Cross sections of the samples were prepared using a focused ion beam (FEI Helios NanoLab 660 DualBeam FIB) operating at $30 \mathrm{kV}$ accelerating voltage and all SEM images were taken using the same microscope. Sheet resistance and transmittance of the electrodes and semitransparent devices were measured using a four-point probe and an UV-VIS-NIR spectrometer (Lambda 950, from Perkin), respectively.

In order to determine the complex refractive index of perovskite film, four perovskite films were prepared on an oxygen plasma pretreated glass by spin coating the aforementioned solution in an inert atmosphere. Then, reflection and transmission spectra under perpendicular light incidence were measured in the wavelength region of 350-800 nm with an UV/ Vis spectrometer equipped with an integrating sphere. Finally, the complex refractive index $\tilde{n}(\lambda)$ was calculated by the software NIKA (http://lpvo.fe.uni-lj.si/en/software/nika/)

\section{Acknowledgements}

The work was supported by the Solar Technologies go Hybrid (SolTech) and the Cluster of Excellence "Engineering of
Advanced Materials" (EAM) at the University of ErlangenNuremberg. We thank Ulrike Marten-Jahns from the "Chair of Surface Science and Corrosion" for the XRD characterization. K. F. gratefully acknowledges use of the services and facilities of the Energie Campus Nürnberg and financial support through the "Aufbruch Bayern" initiative of the state of Bavaria. T. P. acknowledges funding via the DFG research training group GRK 1896. C. B. acknowledges the support of the EU-project SOLPROCEL ("SOLUTION PROCESSED HIGH PERFORMANCE TRANSPARENT ORGANIC PHOTOVOLTAIC CELLS", grant no. 604506). F. G. would like to thank the funding from the China Scholarship Council.

\section{Notes and references}

1 S. Kazim, M. K. Nazeeruddin, M. Grätzel and S. Ahmad, Angew. Chem., Int. Ed., 2014, 53, 2812-2824.

2 J. Burschka, N. Pellet, S. J. Moon, R. Humphry-Baker, P. Gao, M. K. Nazeeruddin and M. Grätzel, Nature, 2013, 499, 316-319.

3 J. M. Ball, M. M. Lee, A. Hey and H. J. Snaith, Science, 2013, 6, 1739-1743.

4 Z. Xiao, C. Bi, Y. Shao, Q. Dong, Q. Wang, Y. Yuan, C. Wang, Y. Gao and J. Huang, Energy Environ. Sci., 2014, 7, 2619-2623.

5 G. Xing, N. Mathews, S. Sun, S. S. Lim, Y. M. Lam, M. Grätzel, S. Mhaisalkar and T. C. Sum, Science, 2013, 342, 344-347.

6 S. D. Stranks, G. E. Eperon, G. Grancini, C. Menelaou, M. J. Alcocer, T. Leijtens, L. M. Herz, A. Petrozza and H. J. Snaith, Science, 2013, 342, 341-344.

7 A. Kojima, K. Teshima, Y. Shirai and T. Miyasaka, J. Am. Chem. Soc., 2009, 131, 6050-6051.

8 M. Liu, M. B. Johnston and H. J. Snaith, Nature, 2013, 501, 395-398.

9 J. T.-W. Wang, J. M. Ball, E. M. Barea, A. Abate, J. A. Alexander-Webber, J. Huang, M. Saliba, I. Mora-Sero, J. Bisquert, H. J. Snaith and R. J. Nicholas, Nano Lett., 2014, 14, 724-730.

10 P. W. Liang, C. Y. Liao, C. C. Chueh, F. Zuo, S. T. Williams, X. K. Xin, J. Lin and A. K. Y. Jen, Adv. Mater., 2014, 26, 3748-3754.

11 P. Qin, S. Tanaka, S. Ito, N. Tetreault, K. Manabe, H. Nishino, M. K. Nazeeruddin and M. Grätzel, Nat. Commun., 2014, 5, DOI: 10.1038/ncomms4834.

12 J. Y. Jeng, K. C. Chen, T. Y. Chiang, P. Y. Lin, T. D. Tsai, Y. C. Chang, T. F. Guo, P. Chen, T. C. Wen and Y. J. Hsu, Adv. Mater., 2014, 26, 4107-4113.

13 Z. Wu, S. Bai, J. Xiang, Z. Yuan, Y. Yang, W. Cui, X. Gao, Z. Liu, Y. Jin and B. Sun, Nanoscale, 2014, 6, 10505-10510.

14 Z. Li, S. A. Kulkarni, P. P. Boix, E. Shi, A. Cao, K. Fu, S. K. Batabyal, J. Zhang, Q. Xiong, L. H. Wong, N. Mathews and S. G. Mhaisalkar, ACS Nano, 2014, 8, 6797-6804.

15 G. E. Eperon, V. M. Burlakov, A. Goriely and H. J. Snaith, ACS Nano, 2013, 8, 591-598. 
16 C. Roldán-Carmona, O. Malinkiewicz, R. Betancur, G. Longo, C. Momblona, O. Malinkiewicz, R. Betancur, G. Longo and C. Momblona, Energy Environ. Sci., 2014, 7, 2968-2973.

17 L. K. Ono, S. Wang, Y. Kato, S. R. Raga and Y. Qi, Energy Environ. Sci., 2014, 7, 3989-3993.

18 C. J. Emmott, A. Urbina and J. Nelson, Sol. Energy Mater. Sol. Cells, 2012, 97, 14.

19 A. Mei, X. Li, L. Liu, Z. Ku, T. Liu, Y. Rong, M. Xu, M. Hu, J. Chen, Y. Yang, M. Grätzel and H. Han, Science, 2014, 345, 295-298.

20 L. Zhang, T. Liu, L. Liu, M. Hu, Y. Yang, A. Mei and H. Han, J. Mater. Chem. A, 2014, DOI: 10.1039/C4TA04647A.

21 D. S. Hecht, L. Hu and G. Irvin, Adv. Mater., 2011, 23, 1482-1513.

22 D. S. Leem, A. Edwards, M. Faist, J. Nelson, D. D. Bradley and J. C. de Mello, Adv. Mater., 2011, 23, 43714375.

23 A. Kim, Y. Won, K. Woo, C. H. Kim and J. Moon, ACS Nano, 2013, 7, 1081-1091.

24 F. Guo, T. Ameri, K. Forberich and C. J. Brabec, Polym. Int., 2013, 62, 1408-1412.

25 T. Stubhan, J. Krantz, N. Li, F. Guo, I. Litzov, M. Steidl, M. Richter, G. J. Matt and C. J. Brabec, Sol. Energy Mater. Sol. Cells, 2012, 107, 248-251.

26 F. Guo, X. Zhu, K. Forberich, J. Krantz, T. Stubhan, M. Salinas, M. Halik, S. Spallek, B. Butz, E. Spiecker, T. Ameri, N. Li, P. Kubis, D. M. Guldi, G. J. Matt and C. J. Brabec, Adv. Energy Mater., 2013, 3, 1062-1067.
27 A. Kim, Y. Won, K. Woo, S. Jeong and J. Moon, Adv. Funct. Mater., 2014, 24, 2462-2471.

28 X. Li, Y. Jung, J. S. Huang, T. Goh and A. D. Taylor, Adv. Energy Mater., 2014, DOI: 10.1002/aenm.201400186.

29 G. Y. Margulis, M. G. Christoforo, D. Lam, Z. M. Beiley, A. R. Bowring, C. D. Bailie, A. Salleo and M. D. McGehee, Adv. Energy Mater., 2013, 3, 1657-1663.

30 P. Docampo, J. M. Ball, M. Darwich, G. E. Eperon and H. J. Snaith, Nat. Commun., 2013, 4, DOI: 10.1038/ ncomms3761.

31 F. Guo, P. Kubis, T. Stubhan, N. Li, D. Baran, T. Przybilla, E. Spiecker, K. Forberich and C. J. Brabec, ACS Appl. Mater. Interfaces, 2014, 6, 18251-18257.

32 F. Guo, P. Kubis, N. Li, T. Przybilla, G. Matt, T. Stubhan, T. Ameri, B. Butz, E. Spiecker, K. Forberich and C. J. Brabec, ACS Nano, 2014, DOI: 10.1021/nn505559w.

33 M. Graetzel, R. A. J. Janssen, D. B. Mitzi and E. H. Sargent, Nature, 2012, 488, 304-312.

34 H. Ma, H. L. Yip, F. Huang and A. K. Y. Jen, Adv. Funct. Mater., 2010, 20, 1371-1388.

35 H. Zhang, H. Azimi, Y. Hou, T. Ameri, T. Przybilla, E. Spiecker, M. Kraft, U. Scherf and C. J. Brabec, Chem. Mater., 2014, 26, 5190-5193.

36 A. Čampa, J. KRČ, F. Smole and M. TOPIČ, Proceedings. Ljubljana: MIDEM - Society for Microelectronics, Electronic Components and Materials, 2005, 285-290.

37 S. Sun, T. Salim, N. Mathews, M. Duchamp, C. Boothroyd, G. Xing, T. C. Sun and Y. M. Lam, Energy Environ. Sci., 2014, 7, 399-407. 